University of Rhode Island

DigitalCommons@URI

Civil \& Environmental Engineering Faculty

Publications

Civil \& Environmental Engineering

2020

\title{
Sulfite activation changes character of ferrate resultant particles
}

\author{
Bradley M. Bzdyra \\ University of Rhode Island \\ Charles D. Spellman Jr. \\ University of Rhode Island \\ Irene Andreu \\ University of Rhode Island \\ Joseph E. Goodwill \\ University of Rhode Island, goodwill@uri.edu
}

Follow this and additional works at: https://digitalcommons.uri.edu/cve_facpubs

The University of Rhode Island Faculty have made this article openly available.

Please let us know how Open Access to this research benefits you.

This is a pre-publication author manuscript of the final, published article.

Terms of Use

This article is made available under the terms and conditions applicable towards Open Access

Policy Articles, as set forth in our Terms of Use.

\section{Citation/Publisher Attribution}

Bradley M. Bzdyra, Charles D. Spellman, Irene Andreu, Joseph E. Goodwill, Sulfite activation changes character of ferrate resultant particles, Chemical Engineering Journal, Volume 393, 2020, 124771, ISSN 1385-8947, https://doi.org/10.1016/j.cej.2020.124771 Available at: https://doi.org/10.1016/ j.cej.2020.124771

This Article is brought to you for free and open access by the Civil \& Environmental Engineering at DigitalCommons@URI. It has been accepted for inclusion in Civil \& Environmental Engineering Faculty Publications by an authorized administrator of DigitalCommons@URI. For more information, please contact digitalcommonsgroup@uri.edu. 


\title{
Sulfite Activation Changes Character of Ferrate Resultant Particles
}

Bradley M. Bzdyra ${ }^{\mathrm{a}, 1}$, Charles D. Spellman Jr. ${ }^{\mathrm{a}, 1}$, Irene Andreu ${ }^{\mathrm{b}}$, Joseph E. Goodwilla,

a University of Rhode Island, Dept. of Civil \& Environmental Engineering, Kingston, RI, USA

b University of Rhode Island, Dept. of Chemical Engineering, and RI Consortium for

Nanoscience \& Nanotechnology, Kingston, RI, USA

*corresponding author, email: goodwill@uri.edu

${ }^{1}$ These authors contributed equally

\section{Graphical Abstract}

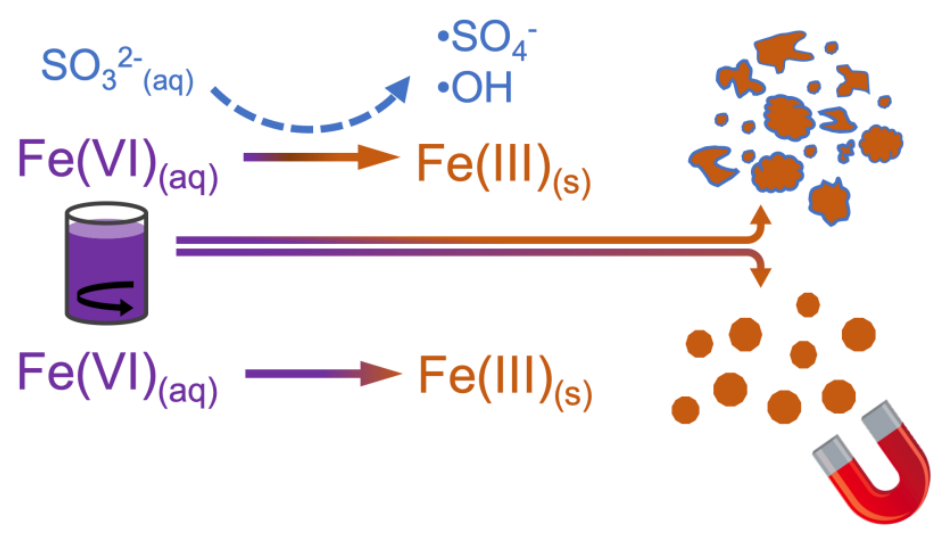

\section{HIGHLIGHTS}

- Sulfite activation results in less magnetic resultant iron particles

- Activation further influences particle morphology and size distribution

- Sulfite activation may impede downstream physiochemical water treatment processes

\begin{abstract}
The activation of ferrate with sulfite increases oxidative transformation of recalcitrant organic compounds; however, it also changes the characteristics of the iron particulates that result from the ferrate reduction. In this study, particles resulting from ferrate reduction both with and without sulfite were compared in a laboratory matrix simulating water treatment conditions at the bench-scale. Characteristics examined included magnetization, morphology, size, and surface charge. The activation of ferrate with sulfite changed the characteristics of resultant particles in several important ways. Activated ferrate resultant particles were less magnetic, more polydisperse including a higher fraction of nanoparticles, and exhibited a less-crystalline morphology compared to particles resulting from ferrate self-decay. Surface charges between the two particle types were similar, and negative. The relatively rapid formation of $\mathrm{Fe}(\mathrm{III})$ from $\mathrm{Fe}(\mathrm{VI})$ activation leads to particles of different character, likely though a greater supply of precursory low molecular weight iron hydroxo-species. Particles resulting from activated ferrate used as a preoxidant will impact downstream processes in important
\end{abstract}


ways, such as gravimetric or magnetic separations and contaminant adsorption. Ferrate activation presents a possible trade-off between improved oxidation and impeded downstream physicochemical processes, and formation and fate of formed particles warrants consideration.

\section{KEYWORDS}

Activated Ferrate; Iron nanoparticles; Magnetism; Pre-oxidation; Coagulation; Water treatment.

\section{INTRODUCTION}

Ferrate $(\mathrm{Fe}(\mathrm{VI}))$ is a high-valance iron species that is used for oxidative transformation of target compounds. ${ }^{1,2}$ In a water treatment context, the relatively high oxidation potential of $\mathrm{Fe}(\mathrm{VI})$ successfully transforms many inorganic ${ }^{3-5}$ and organic contaminants, ${ }^{6-8}$ as well as disinfection byproduct precursors. ${ }^{-12}$ However, some recalcitrant contaminants of emerging concern are not effectively oxidized by $\mathrm{Fe}(\mathrm{VI})$ at relevant dosages and $\mathrm{pH}$ values. ${ }^{13}$ Oxidation with $\mathrm{Fe}(\mathrm{VI})$ can be improved by "activation" of $\mathrm{Fe}(\mathrm{VI})$ by common chemical reducing agents, ${ }^{14}$ acids, ${ }^{15}$ carbon nanotubes, ammonia, ${ }^{16}$ and ultraviolet light. ${ }^{17}$ Disagreement in the literature exists with respect to exact mechanisms of activation, and vary with activation approach; however, an important role of ephemeral iron species (e.g. Fe(V) and Fe(IV)) is likely.

When sulfite is used as the activating agent, the formation of sulfate and hydroxyl radicals also increases oxidation, ${ }^{18}$ and most published research on activated $\mathrm{Fe}(\mathrm{VI})$ has focused on this approach. ${ }^{19,20}$ For example, oxidation of benzotriazole, phenol, ciprofloxacin and sulfamethoxazole all increased from less than 10\% to greater than $75 \%$ when $50 \mu \mathrm{M} \mathrm{Fe}(\mathrm{VI})$ was activated with $250 \mu \mathrm{M}$ of sulfite (1:4 molar ratio). ${ }^{21}$ In this way activated $\mathrm{Fe}(\mathrm{VI})$ represents an emerging advanced oxidation technology for enhanced degradation of organic contaminants. ${ }^{18}$ 
Prior work on $\mathrm{Fe}(\mathrm{VI})$ activated with sulfite (and other reductants) provides important data towards potential adaptation; however, most prior work has been executed in a phosphate buffer to sequester Fe(III) solids that result from Fe(VI) reduction. This dramatically simplifies required analytical steps but prohibits any assessment of resultant particles, ${ }^{22}$ which blocks vertical advancement of sulfite-activated Fe(VI). Particles resulting from Fe(VI) self-decay (e.g. non-activated) have shown unique and important properties, including a core-shell architecture, ${ }^{23}$ participation in adsorption reactions 3,24 and coagulation, ${ }^{10,25,26}$ magnetism, ${ }^{27}$ relatively small size, ${ }^{28}$ and poor settleability. ${ }^{29}$ It is yet unknown how reduction of $\mathrm{Fe}(\mathrm{VI})$ with sulfite may impact these particle characteristics. The overarching objective of this work was to fill this urgent research gap with an assessment of Fe(III) particles resulting from sulfite activated $\mathrm{Fe}(\mathrm{VI})$. Specifically, the characterization included an assessment of magnetism, morphology, size, and surface charge.

\section{METHODS AND MATERIALS}

2.1. Particle Formation Reaction. High-purity potassium ferrate $\left(\mathrm{K}_{2} \mathrm{FeO}_{4}\right)$ (Element 26 Technology, League City, TX) was added to reagent grade water buffered with $1 \mathrm{mM}$ carbonate at $\mathrm{pH}$ 7.5. The Fe(VI) dose was $100 \mu \mathrm{M}(5.6 \mathrm{mg} / \mathrm{L}$ as Fe), confirmed via absorption at $510 \mathrm{~nm} .3^{30}$ The 1 liter reactors were mixed vigorously (G > $200 \mathrm{sec}^{-1}$ ) for one minute, then gradually $\left(\mathrm{G} \sim 50 \mathrm{sec}^{-1}\right)$. Water matrix ( $\mathrm{pH}$ and buffer capacity) and dosing conditions were set to replicate a plausible, low organic carbon water treatment scenario. In Fe(VI) auto-decay experiments, complete Fe(VI) autodecay was confirmed via ABTS method, ${ }^{31}$ following 60 minutes reaction time. In sulfite 
activation experiments, $400 \mu \mathrm{M} \mathrm{SO}_{3}^{-2}$ as a $0.25 \mathrm{M} \mathrm{Na}_{2} \mathrm{SO}_{3}$ stock solution was added to the reactor 30 seconds after $\mathrm{Fe}(\mathrm{VI})$, following a similar protocol from prior research focused on activate $\mathrm{Fe}(\mathrm{VI})$ oxidation. ${ }^{18}$

2.2. Particle Characterizations. Resulting particle size and surface charge were quantified by dynamic light scattering (DLS) and electrophoretic mobility (Malvern Zetasizer Nano ZS). Particle morphology was imaged with transmission electron microscopy (TEM) (JEM-2100, JOEL, Tokyo, Japan). Resulting particle suspensions for TEM were filtered through a glass-fiber (GF) filter (Whatman, 934AH), with an effective cut-off of $1.5 \mu \mathrm{m}$ to remove large aggregates. Particles in GF filtrate were then loaded onto a $30 \mathrm{kDa}$ ultrafilter (UF). The UF was submerged and sonicated in reagent grade water, with resuspended particles then drop-casted and air dried on a $\mathrm{C}$ film with $\mathrm{Cu}$ grid. Particles analyzed by scanning electron microscopy (SEM) (Zeiss Sigma VP, Overkochen, Germany) were prepared by drop casting the as-prepared particle suspension. Crystallinity was evaluated via X-ray powder diffraction (XRD) (Ultima IV, Rigaku, Tokyo, Japan), with a $\mathrm{Cu} \mathrm{K}_{\alpha}$ source at $0.5 \mathrm{deg} / \mathrm{min}$ scan speed. The as-prepared ferrate resultant particles were collected on a $0.7 \mu \mathrm{m}$ cut-off glass fiber fine (GF/F) filter and transferred to the XRD holder for analysis. A sample of GF/F effluent was also subjected to DLS measurements.

2.3. Evaluation of Magnetism. Magnetism was assessed using in situ and ex situ approaches. In situ assessment included transfer of particle suspension to a $10 \mathrm{~mm}$ spectrophotometer cell. One, $9.5 \mathrm{~mm}$ diameter N40 grade neodymium-iron-boron disc 1 T magnet was affixed to the bottom of the cell on the outside. The apparatus was placed 
in a spectrophotometer, and optical density (abs. at $600 \mathrm{~nm}$ ) was tracked over 30 minutes; the optical density over time was normalized to the optical density at the start of the settling experiment. Experiments were repeated with and without the magnet. Ex situ magnetization was measured using a magnetic properties measurement system (MPMS-3 from Quantum Designs, San Diego, USA). 1.5 L of Fe(VI) particle suspension was centrifuged at $4200 \mathrm{~g}$. The supernatant was removed and the pellet was dried in an oven at $80^{\circ} \mathrm{C}$ for $24 \mathrm{~h}$. Approximately $20 \mathrm{mg}$ of powder sample was loaded into the magnetometer and a full cycle from $-5 \mathrm{~T}$ to $+5 \mathrm{~T}$ was acquired in $\mathrm{DC}$ mode at $26.85^{\circ} \mathrm{C}$.

\subsection{Statistical and Other Information. Particle formation reactions and} subsequent characterizations were conducted in triplicate unless otherwise noted. Graphical error bars represent one standard deviation. More statistical and experimental information is included in Supplementary Information (see SI-S1).

\section{RESULTS}

3.1. Activation and Magnetism. Fe(VI) decay without sulfite addition (nonactivated ferrate resultant particles, NFRPs) resulted in particles that were separated from fluid by a magnetic field more so than by gravity alone (Figure 1A). After $30 \mathrm{~min}$, the optical densities of the NFRP suspension without and with a magnet were 0.92 and 0.86 , respectively. For activated $\mathrm{Fe}(\mathrm{VI})$ resultant particles (AFRPs) the optical density both with and without a magnetic were $>0.96$, indicating decreased gravity settling, and negligible impact of a magnetic field (Figure 1B). Results for AFRPs were similar to ferric chloride coagulant control (Figure S1). Both particle types settled poorly, a known 
attribute of $\mathrm{Fe}(\mathrm{VI})$ resultant particles; 29 however, only nonactivated particles showed appreciable increase in separation due to a magnetic field.

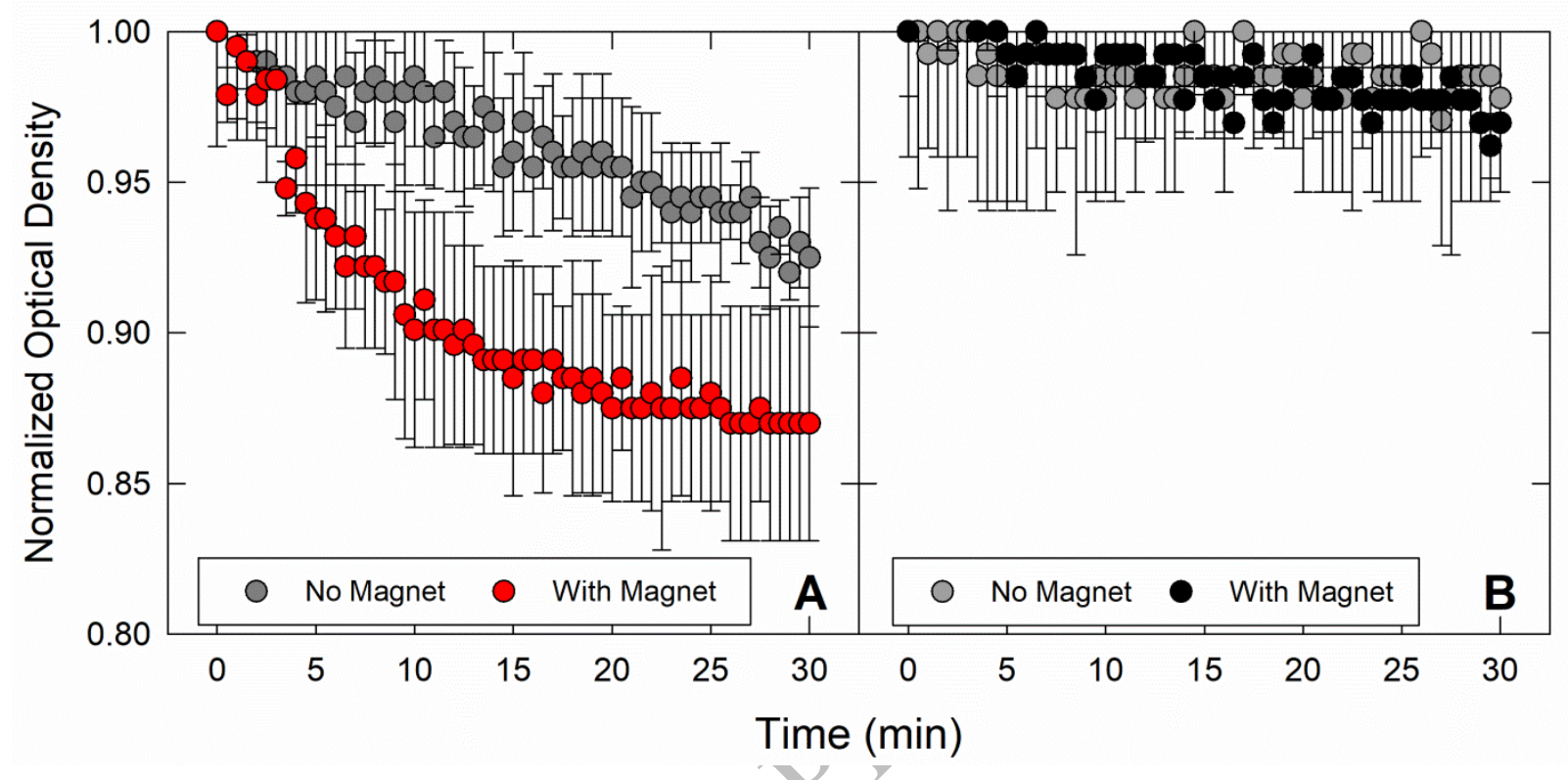

Figure 1. Normalized optical density (absorbance at $600 \mathrm{~nm}$ ) of particle suspensions resulting from (A) Nonactivated ferrate auto-decay and (B) ferrate activated with sulfite. $\mathrm{pH}=7.5, \mathrm{Fe}(\mathrm{VI})$ dose $=100 \mu \mathrm{M}, 1 \mathrm{mM} \mathrm{HCO}_{3}^{-}, 400 \mu \mathrm{M} \mathrm{SO}_{4}^{-2}$.

Figure 2 shows the mass-normalized magnetization (M) versus magnetic field strength $(\mathrm{M}(\mathrm{H}))$ curves near room temperature for both particle types. The nonactivated resultant particles had higher M than AFRPs. This indicates that the portion of ferrimagnetic materials is higher in the nonactivated particles. Additionally, magnetization at high field ( $>3 \mathrm{~T}$,) follows a positive, linear trend with $\mathrm{H}$, with similar slopes (0.07 vs. $0.05 \mathrm{emu} / \mathrm{g} \bullet \mathrm{T})$, characteristic of paramagnetic materials. Insert B in Figure 2 includes $\mathrm{M}(\mathrm{H})$ cycles after paramagnetic subtraction.

Results are consistent with prior work demonstrating that nonactivated $\mathrm{Fe}(\mathrm{VI})$ resultant particles exhibit core-shell architecture with a $\gamma-\mathrm{Fe}_{2} \mathrm{O}_{3}$ (maghemite; ferrimagnetic) core 
and a $\gamma$-FeOOH (lepidocrocite; paramagnetic) shell. ${ }^{23,27}$ It is important to note, however, that sulfite activation changes the resulting particle architecture by decreasing the ferrimagnetic component.

By subtracting the paramagnetic contribution and assuming that the ferrigmanetic contribution is exclusively maghemite with a saturation magnetization $\left(\mathrm{M}_{\mathrm{s}}\right)$ of 414 $\mathrm{kA} / \mathrm{m},{ }^{2}$ it is estimated that NFRPs contain approximately $0.16 \%$ maghemite, while AFRPs contained $0.09 \%$ maghemite, on a mass basis. The lack of hysteresis in the $\mathrm{M}(\mathrm{H})$ cycle indicates the ferrimagnetic component of the particle structure is in the superparamagnetic regime. Superparamagnetism at room temperature is observed for spherical maghemite particles with diameters below $10 \mathrm{~nm} \cdot 3^{2}$

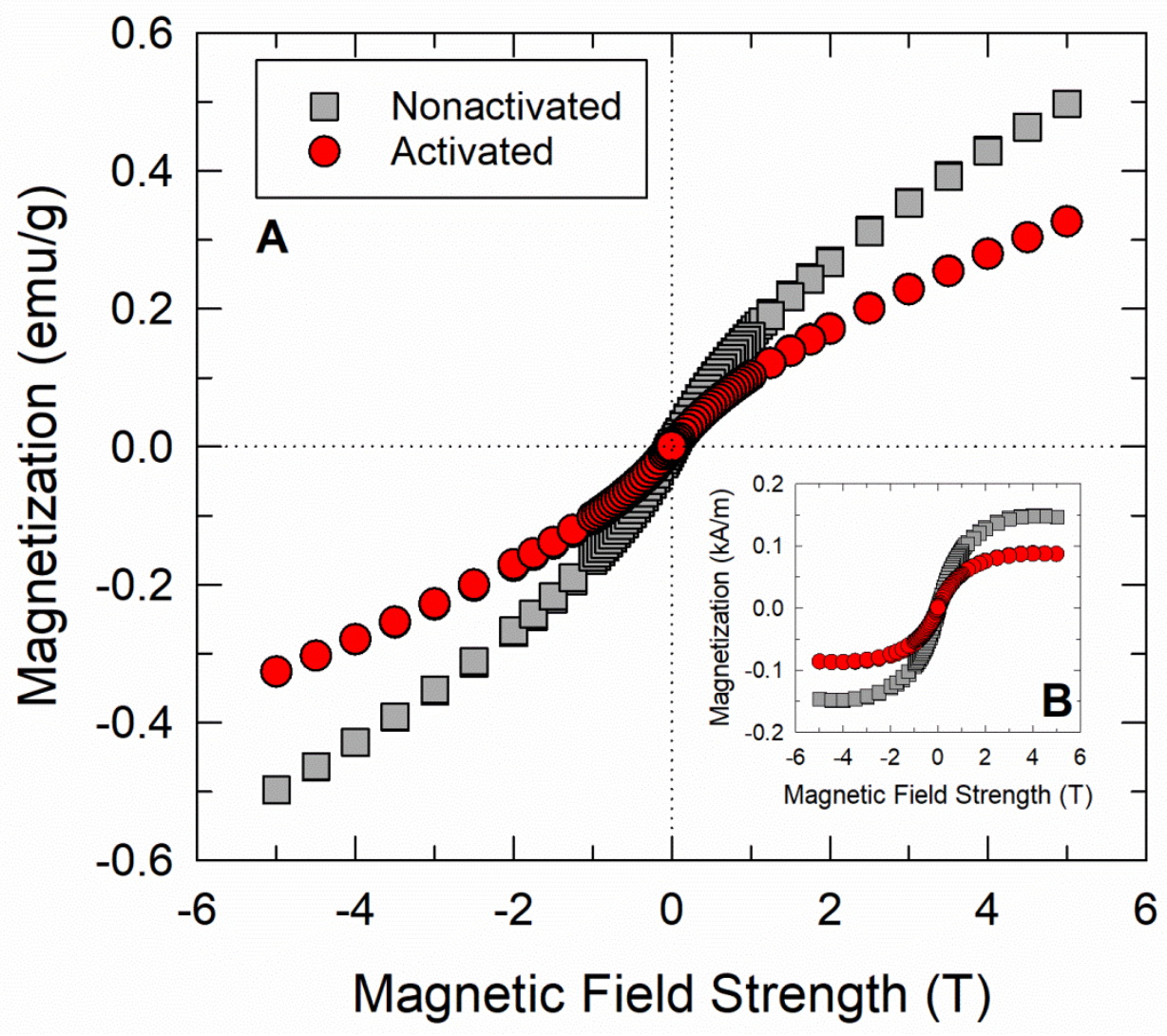


Figure 2. (A): Magnetization (emu/g) of the non-activated and activated Fe(VI) resultant particles as a function of applied magnetic field. Data collected and room temperature and normalized by mass of solids. (B): magnetization in $\mathrm{kA} / \mathrm{m}$ after paramagnetic subtraction, assuming the ferromagnetic material is maghemite.

3.2. Size and Morphology. Sulfite activation changed the size distribution and morphology of $\mathrm{Fe}(\mathrm{VI})$ resultant particles (Figure 3). Both particle types had bimodal distributions with size features in the nanometer and micrometer size range. The intensity-weighted mean particle size ( $\mathrm{d}_{\mathrm{ave}}$ ) for nonactivated and activated $\mathrm{Fe}(\mathrm{VI})$ resultant particles were 1.72 and $2.49 \mu \mathrm{m}$, respectively. AFRPs were more polydisperse than NFRPs with log normal standard deviations $\left(\sigma_{\log }\right)$ of 1.98 and $2.14 \mathrm{~nm}$, respectively. AFRPs were least prominent in the $1-2 \mu \mathrm{m}$ size range, compared to nonactivated particles which were most common in that range. NFRPs resulted in $\sim 90 \%$ of cumulative intensity response occurring below $2 \mu \mathrm{m}$, while AFRPs resulted in $\sim 50 \%$. Below $2 \mu \mathrm{m}$ diameter, the first distribution $\mathrm{d}_{\mathrm{ave}}$ changes to $1091 \mathrm{~nm}$ and $511 \mathrm{~nm}$ for NFRPs and AFRPs, respectively (see Table S1). GF/F DLS results were similar, showing a difference in the submicron size range (Figure 3, panels A and C), after larger particles have been removed. On a mass basis, $>98 \%$ of all Fe was retained on the GF/F filter, indicating that both particle types were almost all $>0.7 \mu \mathrm{m}$, and likely above the measurement range of the DLS instrument, due to limited diffusion.

Very low counts were noted below $100 \mathrm{~nm}$ in all GF/F DLS measurements, indicating a low concentration of nanoparticles, however, particles of that size or smaller were captured via TEM analysis (see Figure 3B and 3D), following particulate concentration from GF/F effluent on the $30 \mathrm{kDa}$ membrane UF. Nanoparticle morphology was different between the NFRPs (Figure 3B) and AFRPs (Figure 3D). NFRPs TEM images 
had clearly defined regions of contrast compared to AFRPs, indicating greater crystallinity, and appeared to contain aggregates of $<10 \mathrm{~nm}$ nanoparticles-a trend noted in prior TEM investigations, although precipitation condition varied.23,29,33 SEM also showed more defined nanoparticles for the NFRP than the AFRP (see Figure SI S3 and S4). XRD results indicated, however, that NFRPs were amorphous (see Figure S2). This apparent disagreement is attributable to the size and architecture of nanoscale NFRPs and the large fraction of non-magnetic material: nanoscale maghemite may appear amorphous to XRD due to loss of symmetry near the surface of the particle, and poorly crystalline $\gamma$-FeOOH shells and other amorphous phases may obscure the underlying more-crystalline $\gamma-\mathrm{Fe}_{2} \mathrm{O}_{3}$ core of NFRPS. ${ }^{27}$ 


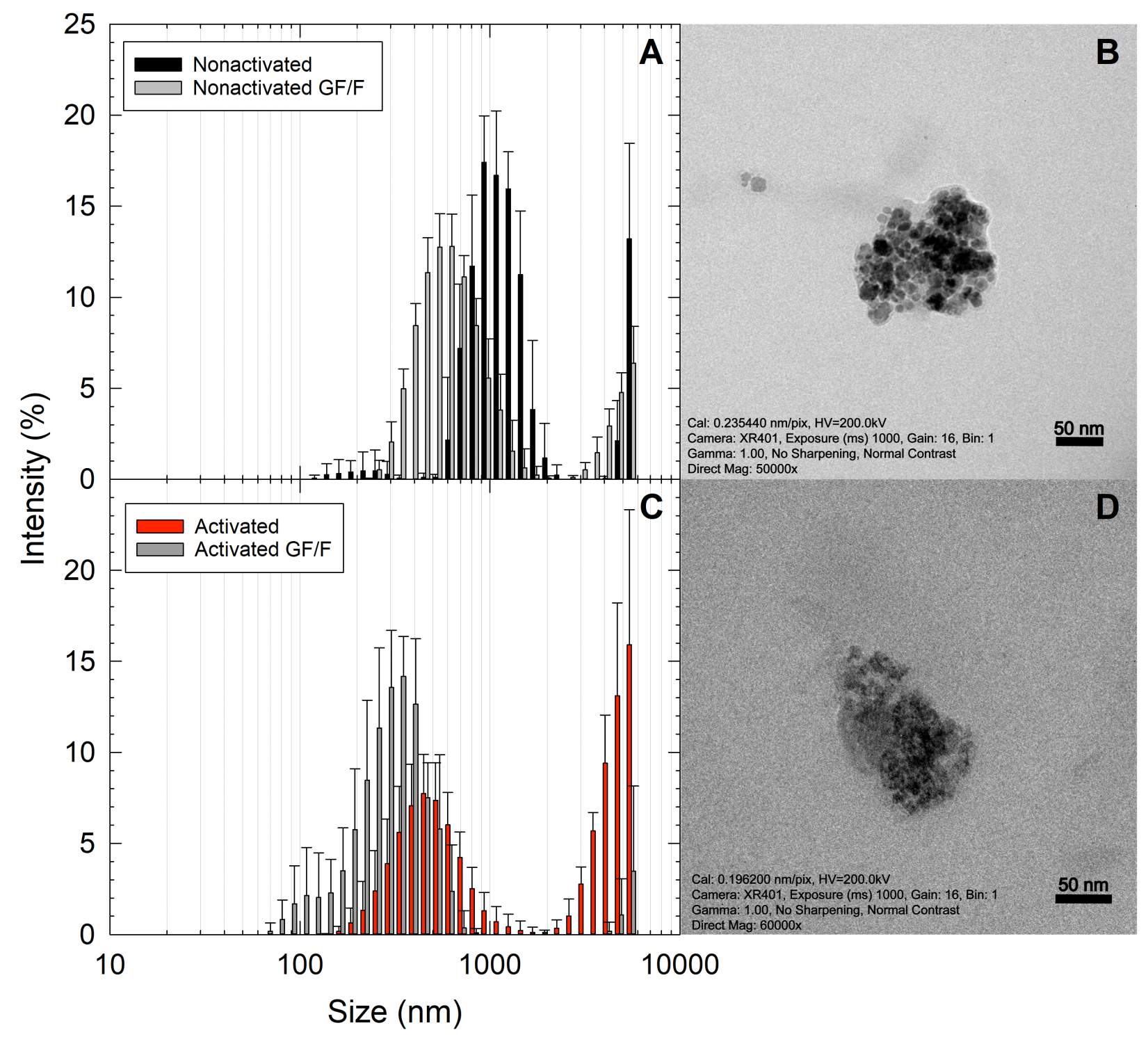

Figure 3. Left, particle size distributions for nonactivated (A) and activated (C) ferrate resultant particles before and after a glass fiber fine (GF/F) filter. Right, transmission electron microscopy (TEM) images of nonactivated (B) and activated (D) ferrate resultant particles. Scale bar represents $50 \mathrm{~nm}$ in each TEM image.

3.3. Surface Charge. Particles resulting for both formation reactions had negative surface charges, representing a relatively stable colloidal suspension. Sulfite activation had only minor impacts on the surface charge of resultant particles (see SI-S6 and Figure S5 for more details). 


\section{DISCUSSION \& CONCLUSION}

4.1. Mechanistic Interpretation. The differences in characteristics between NFRPs and AFRPs suggest differences in precipitation mechanism attributable to the presence of sulfite/sulfate. An stoichiometrically-excessive amount of sulfite will reduce $\mathrm{Fe}(\mathrm{VI})$ to $\mathrm{Fe}(\mathrm{III})$ rapidly $\left(\mathrm{k}>10^{12} \mathrm{M}^{-1} \mathrm{~s}^{-1}\right), 34$ resulting in near-instantaneous formation of $\mathrm{Fe}(\mathrm{III})$ and $\mathrm{SO}_{4}^{-2}$. $\mathrm{Fe}(\mathrm{VI})$ auto-decay produces $\mathrm{Fe}(\mathrm{III})$ at a rate many orders of magnitude slower at $\mathrm{pH} 7.5\left(\mathrm{k} \sim 20 \mathrm{M}^{-1} \mathrm{~S}^{-1}\right) .22,35$ Ferric-oxide particles typically form by growth of nuclei fed by low-molecular weight iron species (e.g. dimeric iron hydroxo-species), with the ultimate form and crystallinity dedicated by the rate at which these species are supplied.36,37 The more slowly the species are supplied, as in Fe(VI) auto-decay, the better ordered phases that result.38,39 Therefore, the slower "supply" of Fe(III) resulting from nonactivated $\mathrm{Fe}(\mathrm{VI})$ would set conditions for more crystalline structures, while activation likely leads to more amorphous structures (Figure 3). This mechanistic difference could apply to any mode of $\mathrm{Fe}(\mathrm{VI})$ activation that drastically accelerates the rate of decay. The presence of sulfate resulting from sulfite-based Fe(VI) activation may also specifically impact particle precipitation mechanisms. Sulfate forms complexes with Fe(III), and may impact particle formation in several ways, including increasing the rate of precipitation compared to solutions without divalent anions. 37,40

4.2. Water Treatment Implications. Magnetism of NFRPs has been highlighted as a potential advantage of $\mathrm{Fe}(\mathrm{VI})$ in a water treatment context, as it would allow for magnetically-based particulate separation. ${ }^{23,41} \mathrm{~A}$ force balance on maghemite particles indicates magnetic force is approximately 5 times larger than gravity for particles $0.5 \mathrm{~cm}$ 
away from a $1 \mathrm{~T}$ magnet (see SI-S7). This dominance of magnetism is important, as exclusively gravimetric approaches to NFRP separation are generally effective (Figure 1), ${ }^{29}$ and predicted Stoke's terminal settling velocities for NFRPs are $<3 \mathrm{~mm}$ /day when diameter is $<500 \mathrm{~nm}$. Attractive interparticle magnetic forces may also lead to aggregation of particles, in addition to van der Waals forces, ${ }^{42}$ which in turn could lead to enhanced gravimetric precipitation. Activation of $\mathrm{Fe}(\mathrm{VI})$ has been highlighted as a novel approach to advanced oxidation of recalcitrant organic contaminants. Results here demonstrate that a common method for $\mathrm{Fe}(\mathrm{VI})$ activation decreases subsequent particle magnetism and crystalline-morphology, while also changing the size distribution and settling velocities. In this way, $\mathrm{Fe}(\mathrm{VI})$ activation with sulfite represents a trade-off between improved oxidation and impeded downstream physicochemical processes. In addition, the crystal structure of FRPs is critical to the adsorption of arsenic and other contaminants. ${ }^{27,41}$ Our results show that sulfate activation changes the structure of the ferrate resulting particles, which could lead to a change in contaminant adsorption. Different activation approaches exist, such as sub-stoichiometric and/or staggered sulfite addition, ${ }^{43}$ which may better balance treatment goals. Other important solutes and water quality characteristics (i.e. dissolved organic carbon, $\mathrm{pH}$ ) may impact resultant particle characteristics. Future work on activated Fe(VI) should consider the formation and fate of resultant particles in relevant water matrices, and evaluate the trade-off between improved oxidation of contaminants and reduced settleability, magnetism, and adsorption characteristics of the downstream particles. 


\section{ACKNOWLEDGEMENTS}

Funding provided by U.S. Dept. of Interior, Bureau of Reclamation (R17ACoo133). The expressed views are exclusively those of the authors, not the funding agency. This work made use of the SQUID at the MRSEC Shared Experimental Facilities at MIT, supported by the National Science Foundation under award number DMR-1419807. The TEM, SEM and XRD data was acquired at the RI Consortium for Nanoscience and Nanotechnology, a URI College of Engineering core facility partially funded by the National Science Foundation EPSCoR, Cooperative Agreement \#OIA-1655221.

\section{REFERENCES}

(1) Sharma, V. K.; Chen, L.; Zboril, R. Review on High Valent FeVI (Ferrate): A Sustainable Green Oxidant in Organic Chemistry and Transformation of Pharmaceuticals. ACS Sustain. Chem. Eng. 2016, 4 (1), 18-34.

(2) Sharma, V. Potassium ferrate (VI): an environmentally friendly oxidant. Adv. Environ. Res. 2002, 2002 (6), 143-156.

(3) Lee, Y.; Um, I.; Yoon, J. Arsenic(III) oxidation by iron(VI) (ferrate) and subsequent removal of arsenic(V) by iron(III) coagulation. Environ. Sci. Technol. 2oo3, $37(24), 5750-5756$.

(4) Sharma, V. K. Oxidation of inorganic compounds by Ferrate(VI) and Ferrate(V): one-electron and two-electron transfer steps. Environ. Sci. Technol. 2010, 44 (13), $5148-5152$.

(5) Goodwill; Mai, X.; Jiang, Y.; Reckhow, D. A.; Tobiason, J. E. Oxidation of manganese (II) with ferrate: Stoichiometry, kinetics, products, and impact of organic carbon. Chemosphere 2016, 159, 457-464.

(6) Jiang, W.; Chen, L.; Batchu, S. R.; Gardinali, P. R.; Jasa, L.; Marsalek, B.; Zboril, R.; Dionysiou, D. D.; O'Shea, K. E.; Sharma, V. K. Oxidation of microcystin-LR by ferrate(VI): Kinetics, degradation pathways, and toxicity assessments. Environ. Sci. Technol. 2014, 48 (20), 12164-12172.

(7) Lee, Y.; Yoon, J.; von Gunten, U. Kinetics of the oxidation of phenols and phenolic endocrine disruptors during water treatment with ferrate (Fe(VI)). Environ. Sci. Technol. 2005, 39 (22), 8978-8984.

(8) Yang, B.; Ying, G.-G.; Zhao, J.-L.; Zhang, L.-J.; Fang, Y.-X.; Nghiem, L. D. Oxidation of triclosan by ferrate: reaction kinetics, products identification and toxicity evaluation. J. Hazard. Mater. 2011, 186 (1), 227-235.

(9) Jiang, Y.; Goodwill, J. E.; Reckhow, D. A.; Tobiason, J. E. Impacts of ferrate oxidation on natural organic matter and disinfection byproduct precursors. Water Res.

2016, 96, 114-125.

(10) Goodwill, J. E.; Jiang, Y.; Reckhow, D. A.; Tobiason, J. E. Laboratory assessment 
of ferrate for drinking water treatment. J. Am. Water Work. Assoc. 2016, 108 (3), 164174.

(11) Gan, W.; Sharma, V. K.; Zhang, X.; Yang, L.; Yang, X. Investigation of disinfection byproducts formation in ferrate(VI) pre-oxidation of NOM and its model compounds followed by chlorination. J. Hazard. Mater. 2015, 292, 197-204.

(12) Li, C.; Luo, F.; Dong, F.; Zhao, J.; Zhang, T.; He, G.; Cizmas, L.; Sharma, V. K. Chlorine decay and trihalomethane formation following ferrate(VI) preoxidation and chlorination of drinking water. Chemosphere 2017, 187, 413-420.

(13) Sharma, V. K.; Zboril, R.; Varma, R. S. Ferrates: Greener Oxidants with Multimodal Action in Water Treatment Technologies. Acc. Chem. Res. 2015 , 150210093927009 .

(14) Feng, M.; Jinadatha, C.; McDonald, T. J.; Sharma, V. K. Accelerated Oxidation of Organic Contaminants by Ferrate(VI): The Overlooked Role of Reducing Additives.

Environ. Sci. Technol. 2018, 52 (19), 11319-11327.

(15) Manoli, K.; Nakhla, G.; Ray, A. K.; Sharma, V. K. Enhanced oxidative transformation of organic contaminants by activation of ferrate(VI): Possible involvement of FeV/FeIVspecies. Chem. Eng. J. 2017, 307, 513-517.

(16) Feng, M.; Cizmas, L.; Wang, Z.; Sharma, V. K. Activation of ferrate(VI) by ammonia in oxidation of flumequine: Kinetics, transformation products, and antibacterial activity assessment. Chem. Eng. J. 2017, 323, 584-591.

(17) Shaohua Wu, Haiyang Liu, Yan Lin, Chunping Yang, Wei Lou, Jianteng Sun, Cheng Du, Dongmei Zhang, Lijun Nie, KaiYin, Y.Z. Insights into mechanisms of $\mathrm{UV} /$ ferrate oxidation for degradation of phenolic pollutants: Role of superoxide radicals. Chemosphere 2019, 244, 125490.

(18) Sun, S.; Pang, S. Y.; Jiang, J.; Ma, J.; Huang, Z.; Zhang, J.; Liu, Y.; Xu, C.; Liu, Q.; Yuan, Y. The combination of ferrate(VI) and sulfite as a novel advanced oxidation process for enhanced degradation of organic contaminants. Chem. Eng. J. 2018, 333 (July 2017), 11-19.

(19) Shao, B.; Dong, H.; Sun, B.; Guan, X. Role of Ferrate(IV) and Ferrate(V) in Activating Ferrate(VI) by Calcium Sulfite for Enhanced Oxidation of Organic Contaminants. Environ. Sci. Technol. 2019, 53 (2), 894-902.

(20) Feng, M.; Sharma, V. K. Enhanced oxidation of antibiotics by ferrate(VI)sulfur(IV) system: Elucidating multi-oxidant mechanism. Chem. Eng. J. 2018, 341 (December 2017), 137-145.

(21) Zhang, J.; Zhu, L.; Shi, Z.; Gao, Y. Rapid removal of organic pollutants by activation sulfite with ferrate. Chemosphere 2017, 186, 576-579.

(22) Jiang, Y.; Goodwill, J. E.; Tobiason, J. E.; Reckhow, D. A. Effect of Different Solutes, Natural Organic Matter, and Particulate Fe(III) on Ferrate(VI) Decomposition in Aqueous Solutions. Environ. Sci. Technol. 2015, 49, 2841-2848.

(23) Kralchevska, R. P.; Prucek, R.; Kolař́lk, J.; Tuček, J.; Machala, L.; Filip, J.; Sharma, V. K.; Zbořil, R. Remarkable efficiency of phosphate removal: Ferrate(VI)induced in situ sorption on core-shell nanoparticles. Water Res. 2016, 103, 83-91. (24) Xie, X.; Cheng, H. A simple treatment method for phenylarsenic compounds: Oxidation by ferrate (VI) and simultaneous removal of the arsenate released with in situ formed Fe(III) oxide-hydroxide. Environ. Int. 2019, 127 (March), 730-741.

(25) Ma, J.; Liu, W. Effectiveness of ferrate (VI) preoxidation in enhancing the coagulation of surface waters. Water Res. 2002, 36 (20), 4959-4962. 
(26) Ma, J.; Liu, W. Effectiveness and mechanism of potassium ferrate(VI) preoxidation for algae removal by coagulation. Water Res. 2002, 36 (4), 871-878.

(27) Prucek, R.; Tuček, J.; Kolař́́k, J.; Filip, J.; Marušák, Z.; Sharma, V. K.; Zbořil, R. Ferrate(VI)-induced arsenite and arsenate removal by in situ structural incorporation into magnetic iron(III) oxide nanoparticles. Environ. Sci. Technol. 2013, 47 (7), 32833292.

(28) Goodwill, J. E.; Jiang, Y.; Reckhow, D. A.; Gikonyo, J.; Tobiason, J. E. Characterization of Particles from Ferrate Preoxidation. Environ. Sci. Technol. 2015, 49, 4955-4962.

(29) Zheng, L.; Deng, Y. Settleability and characteristics of ferrate(VI)-induced particles in advanced wastewater treatment. Water Res. 2016, 93, 172-178.

(30) Rush, J. D. J.; Zhao, Z.; Bielski, B. H. J. B. Reaction of Ferrate(VI)/Ferrate(V) with Hydrogen Peroxide and Superoxide Anion - A Stopped-Flow and Premix Pulse Radiolysis Study. Free Radic. Res. 1996, 24 (3), 187-198.

(31) Lee, Y.; Yoon, J.; von Gunten, U. Spectrophotometric determination of ferrate (Fe(VI)) in water by ABTS. Water Res. 2005, 39 (10), 1946-1953.

(32) Rosensweig, R. E. Heating magnetic fluid with alternating magnetic field. $J$. Magn. Magn. Mater. 2002, 252, 370-374.

(33) Lv, D.; Zheng, L.; Zhang, H.; Deng, Y. Coagulation of colloidal particles with ferrate(vi). Environ. Sci. Water Res. Technol. 2018, 4 (5), 701-710.

(34) Johnson, M. D.; Bernard, J. Kinetics and Mechanism of the Ferrate Oxidation of Sulfite and Selenite in Aqueous Media. Inorg. Chem. 1992, 31 (24), 5140-5142.

(35) Lee, Y.; Kissner, R.; von Gunten, U, Reaction of ferrate(VI) with ABTS and selfdecay of ferrate(VI): kinetics and mechanisms. Environ. Sci. Technol. 2014, 48 (9), 5154-5162.

(36) Dousma, J.; de Bruyn, P. Hydrolysis-Precipitation Studies of Iron Solutions. $J$. Colloid Interface Sci. 1976, 56 (3), 527-539.

(37) Flynn Jr., C. M. Hydrolysis of inorganic iron(III) salts. Chem. Rev. 1984, 84, 3141.

(38) Schwertmann, U.; Friedl, J.; Stanjek, H. From Fe(III) ions to ferrihydrite and then to hematite. J. Colloid Interface Sci. 1999, 209 (1), 215-223.

(39) Cornell, R. M.; Schwertmann, U. The iron oxides: structure, properties, reactions, occurrences and uses, Second.; John Wiley \& Sons: Weinheim, 2003. (40) Sapieszko, R. S.; Patel, R. C.; Matijevic, E. Ferric hydrous oxide sols. 2. Thermodynamics of aqueous hydroxo and sulfato ferric complexes. J. Phys. Chem. 1977, 81 (11), 1061-1068.

(41) Prucek, R.; Tuček, J.; Kolařík, J.; Hušková, I.; Filip, J.; Varma, R. S.; Sharma, V. K.; Zbořil, R. Ferrate(VI)-prompted removal of metals in aqueous media: Mechanistic delineation of enhanced efficiency via metal entrenchment in magnetic oxides. Environ. Sci. Technol. 2015, 49 (4), 2319-2327.

(42) Matijevic, E.; Partch, R. E. Synthesis of monodispersed colloids by chemical reactions in aerosols; Sugimoto, T., Ed.; Marcel Dekker AG: New York, 2000. (43) Shao, B.; Dong, H.; Feng, L.; Qiao, J.; Guan, X. Influence of [sulfite]/[Fe(VI)] molar ratio on the active oxidants generation in $\mathrm{Fe}(\mathrm{VI}) /$ sulfite process. J. Hazard. Mater. 2020, 384 (July 2019), 121303. 